\title{
Exposure to Sound from Nigerian Musicals on Blood Pressure and Pulse Indicators among Volunteer Young Adults in Ibadan, Nigeria
}

\author{
Udoka Shalom Nwabuoku*, Mumuni Adejumo and Mynepalli K C Sridhar \\ Department of Environmental Health Sciences, University of Ibadan, Nigeria
}

Submission: November 11, 2020; Published: December 08, 2020

*Corresponding author: Udoka Shalom Nwabuoku, Department of Environmental Health Sciences, Faculty of Public Health, University of Ibadan, Ibadan, Nigeria

\begin{abstract}
Sound exposure from music is common among Nigerian youths. Studies have reported social benefits of some musical genre sounds to the listeners; however, its effect on the pulse rate and blood pressure among youths has not been adequately explored. Therefore, this study was done to determine the effect of sounds from selected Nigerian musical genres on blood pressure and pulse indicators among young adults in Ibadan, Nigeria. The cross-sectional study involved exposure of 42 consented youths (aged 18 to 35, both boys and girls) to moderated sounds from 4 Nigerian musical genres in a simulated sound studio in Ibadan South-West. A validated semi-structured questionnaire was used to collect information on; respondents' socio-demography, knowledge and practices associated with the effects of the musical sound exposures. Participants were exposed to Hip-Hop, Rhythm and Blues, Fuji, and Reggae musical sound for 20 minutes each. A calibrated electronic sphygmomanometer was used to record pulse rate and blood pressure pre and post-exposure to the selected sounds. Data were analysed using descriptive statistics and $t$-test at $p=0.05$. Participants had equal sex ratio, aged $23.6 \pm 4.4$ years. $54.8 \%$ were students. Majority, (69.0\%) of the respondents indicated always listening to music, at an average duration of $2.12 \pm 2.05$ hours daily. Respondents pulse rate (beats $/ \mathrm{min}$ ) significantly reduced from $84.2 \pm 6.8$ at pre-exposure to $73.4 \pm 6.4,75.1 \pm 11.8,77.3 \pm 8.8$ and $74.5 \pm 7.8$ at post-exposure to R\&B genre, Hip-Hop, Fuji and Reggae musical sound respectively. Blood pressure $(\mathrm{mmHg})$ significantly reduced from a systolic blood pressure of $117.34 \pm 11.6$ at pre-exposure to $104.4 \pm 8.8$, $114.8 \pm 12.2,110.3 \pm 8.7$ and $106.2 \pm 16.9$ at post exposure to R\&B, Hip-Hop, Fuji and Reggae musical sound, respectively. Slower genres such as R\&B, Reggae and Fuji music had pleasurable and significantly reduction effect on pulse rate and systolic blood pressure. Engaging further research, and awareness is essential on the use of Nigerian musical genres in stress management therapy.
\end{abstract}

Keywords: Nigerian Music and Health; Youth Blood Pressure; Music; Health; Psychological sense.

\section{Introduction}

Music has been defined as an organised combination of sounds which can also be classified according to genres,and typically comprises of elements like frequency, rhythm, repetition, beat, density, tone, rhythm,lyrics and loudness [1]. Moreover, elements of music like loudness could endanger human health. For instance, Kock et al. [2] revealed that exposure to sound more than $85 \mathrm{~dB}$ for hours is potentially dangerous. Cardiovascular autonomic function could be affected as we are exposed to various sounds [3]. Musicals of varying types have been reported to have different physiological effects. For example, slow music is expected to lower the heart rate, calm other physiological parameters and bring the psychological sense in a state of low tension and stress while songs with fast beats and high pitches increased the rate of the heartbeat etc. [4].

Music embodies culture, expressing relevant features of a people's life. Indeed, it is difficult to imagine life without music in traditional Nigerian society where all strata and age groups have their own music [5]. Different categories of people listen to indigenous music which are used for various regular purposes such as celebrations, religious worship and many other social and choice activities too. In Nigeria, youths are regular attenders of musical programmes or places where they are regularly exposed to good amount of indigenous musicals [6]. Moreover, modern Nigerian music is gaining a lot of audience as it evolves and young music listeners in particular are increasing [7]. Youths, however, 
listen to increasing amounts of musical genres which range from Afrobeat, Hip hop, Reggae, highlife and Rhythm and Blues (R\&B), Juju, Rap etc.

Nigerian youths constitute more than half of the population and they listen to these musicals and attend indoor musical events regularly. At these indoor youth programmes modern musical genres are usually played repeatedly [6]. Besides dancing, there are other benefits people derive from musical sound. Some people find it as pleasure irrespective of the loudness, and /or pitch [3]. However, there are other perceived benefits of musical sound on human health which sometimes differs from actual effect. However, there are paucity of information on the scientific procedures to check for actual systemic effects of such exposures. Continuous and regular exposure to these different musical genres is common among Nigerian youths, but its effects on the health of our youth need to be adequately explored [1]. This will be useful for public education on health uses of the musical sounds. Therefore, this study was carried out to determine the effect of varying sound types and levels from selected Nigerian musical genres on blood pressure and pulse indicators among young adults in Ibadan, Nigeria.

\section{Methodology}

\section{Study area}

The study was conducted in Ibadan South-West Local Government Area (LGA) in Oyo State, Nigeria. The LGA has 12 wards and its headquarters is in Oluyole Estate in Ibadan. It has an area of $40 \mathrm{~km}^{2}$ and a population of 282,585 people at the 2006 census with an estimated population of 397,700 in 2016 and a change of $+3.46 \% /$ year from 2006 to 2016 (NPC, 2016) [8]. The LGA lies on the position $7.3458^{\circ} \mathrm{N}$ and $3.8757^{\circ} \mathrm{E}$ and some of the popular areas includes; Ring-Road, Oke-Ado, Oke-Bola, Gege, Born-Photo, Isale-Osi e.t.c. Exposure to selected Nigerian musical genre was carried out in a simulated hall at The Dexterity Place (Figure 1), Ring Road, Ibadan. The hall was a sound proof hall with air conditioning with dimensions of $12.19 \mathrm{~m}$ to $6.45 \mathrm{~m}$ width to height ratio respectively, on Longitude 3.86716 and Latitude 7.36048 with an area of $78.63 \mathrm{~m}^{2}$. Other internal conditions of the hall were light intensity of 250 lux, relative humidity of $58.4 \%$, and background sound level of $49.3 \mathrm{~dB}$ at room temperature.

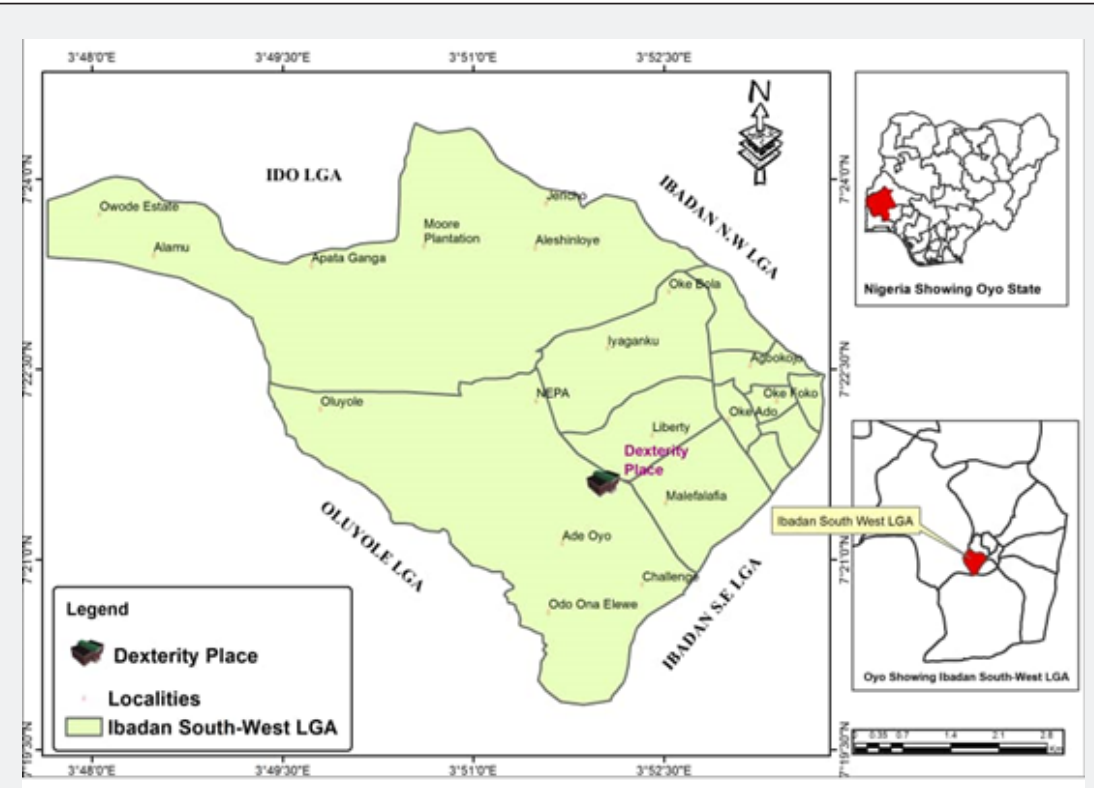

Figure 1: Map of Ibadan South-West Local Government Area, Showing Study Location.

\section{Study design}

This study was a cross-sectional in design which involved exposure of participants to 4-diffrernt types of Nigerian musical genre in a standardized simulated sound studio located at ring road in Ibadan South-West Local Government Area. A pretested, semi-structured, interviewer administered questionnaires was used to collect socio-demographics characteristics of the participants, knowledge of the participants about the use of the selected musical genres and attitude to the use of the selected musical genres. A calibrated Sphygmomanometer was used to record the pulse rate and blood pressure before and after exposure to the 4-different type of moderated genres and pitches of modern Nigerian music.

\section{Study population and sampling techniques}

Consented Young Adult (21 male and 21 female) between the ages of 18-35 years participated in the study. The participants had at least completed secondary school and residing in Ibadan SouthWest Local Government Area during the time of data collection. A 3-stage random sampling techniques was used to select Ibadan 
South-West Local Government in Ibadan, streets and participants. The LGA was selected among the LGAs with more than one validated sound proof hall which were mostly used for musical indoor events. Eligible participants with average Body Mass Indexes (BMI of 18.5 to 24.9) were selected. Eligible participants with low blood pressure (BP of less than $90 \mathrm{mmHg}$ systolic or $60 \mathrm{mmHg}$ diastolic) or high blood pressure (blood pressure of 140/90 mmHg or higher) were excluded. The researchers approached the authority in-charge of the simulated sound studio before the commencement of data collection with a formal letter. Also, formal letters were written to all the participants to obtain permission to participate in the study. The letters also explained the study objectives. Duly completed and signed consent forms were obtained from the participants and the authority in charge of the simulated sound studio. Consented participants were interviewed while pulse rate and blood pressure were recorded before and after exposure to the 4-different type of moderated genres and pitches of modern Nigerian music after the interview.

\section{Musical genres selection}

The genres selected were mainly a mix of modern sounds categorized according to their socio-cultural classifications [6]. The Nigerian musical genre selected were Afrobeat/ Hip Hop, Reggae, Fuji, and Rhythm and Blues.

i. Afrobeat/ Hip Hop is a genre of African musical that involves the native play of a blend of indigenous sounding instruments such as Konga, Snares, Dun Dun etc in African style harmonious rhythm usually for danceable songs or melodies and usually with high tempo. It is mostly associated with Africans and African-Americans and used for dance, youth events, concerts, indoor entertainment and ceremonies often sang with native African languages.

ii. Reggae Music, originally a Jamaican style of musical, includes elements of fast and slow tempo, and the lyrics are usually themed around realities of everyday life, emerging/social/ cultural/political events etc. Reggae artists most times maintain the same trend in the content of their musicals.

iii. Fuji, however, is a music originated as traditionally a Yoruba Nigerian musical. Involving the play of talking drums, dun dun, conga, etc. The play tempo may be fast or slow, but the style of play especially with the Yoruba talking drum, gives it a known identification. This music is usually heard at all kinds of Yoruba ceremonies, celebrations and often adopted by other non-Yoruba people [6].

iv. Rhythm and Blues (R and B) are classified as slow paced, low tempo musicals that usually communicate love, romance, passions etc. Nigerian Blues comprise of Nigerian musicals that fit into this category. R\&B is usually used at weddings, youth events, indoor entertainment etc. It was assumed to be the most soothing type of music because of the slow tempo [9].

For each of the genre plays, the musicals were synchronized using Virtual DJ Software (Figure 2A) to harmonise beats per minute within genres. The software provided more information such as pitch, amplitude, waveform about the selected musical genre. It was also used to harmonize the volume and bits per minute of each of the songs in a genre to achieve similarity of the tempo of songs within each genre. Hence, the songs within each category maintained a regulated same speed, pitch, loudness etc., to reduce the bias effect of varying tempos.
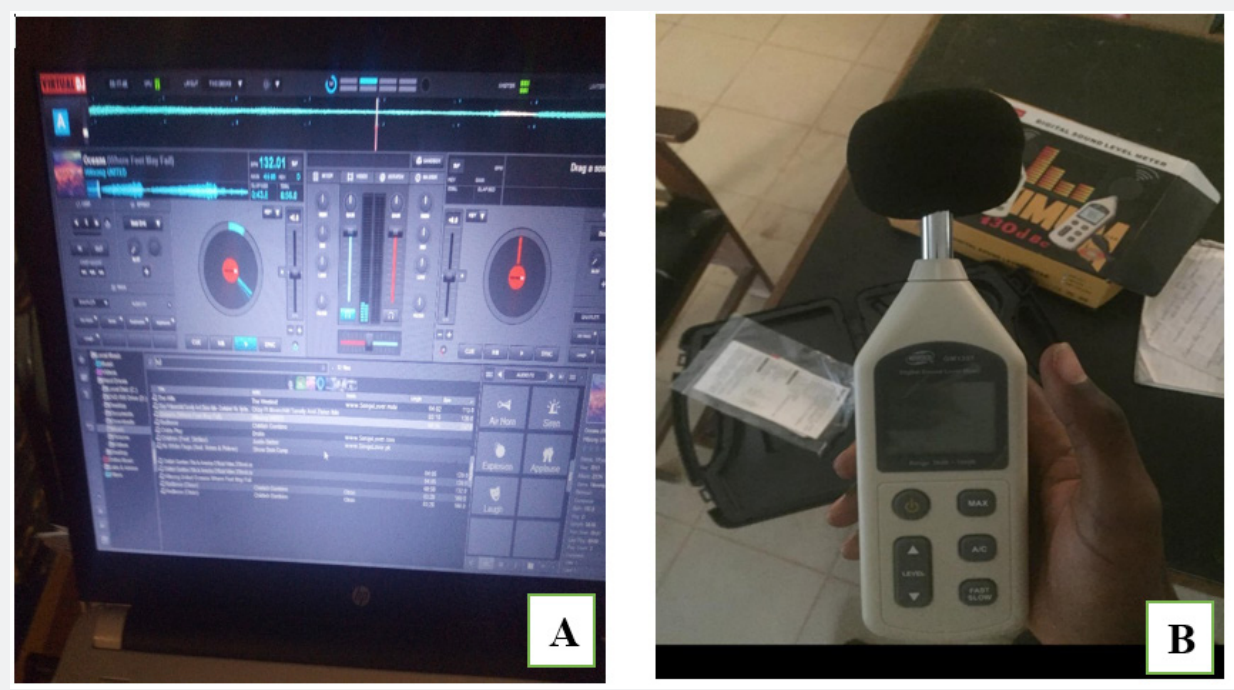

Figure 2: Some measuring device [A-Interface of The Virtual DJ Software; B-Noise level meter]. 


\section{Exposure to musical sound technique and measurement of vital statistics}

Exposure to musical sounds was done in 2-batches. A batch involved 21 participants and the exposure lasted for an average of 3 hours per day. Participants' vital statistics -weight, height, blood pressures and pulse rates were taken. The exposure time for each of four selected genres was 20 minutes, before and during which the blood pressure of each participant was taken. In addition, Noise levels before and during the musical exposure were recorded using a sound level meter. The weight was measured using a digital weighing scale while calibrated meter rule was used to measure the height. The Compact Electronic Sphygmomanometer with pulse checker was used to determine the blood pressure and pulse rate respectively while sound meters (Figure 2B) was used to measure the sound level before and during the exposure period. All the instruments used were standardized before measurement. It was also ensured that the musical volume was maintained within the permissible 85 Decibels. We ensured to avoid parallax error when reading from the scale or tape and ensured accuracy and timeliness in the experiment as blood pressure and pulses were taken as timed within the study. (Figure 2).

\section{Data Analysis}

Data from this study was compiled and properly recorded and analyzed using Statistical Package for Social Sciences (SPSS version 20). Data were analyzed using descriptive statistics and t-test was used to compare the mean BP and heart rate before and after the exposure to the musical sound at $\mathrm{p}=0.005$.

\section{Ethical Considerations}

This study was ethically carried out in safe conditions, with consent of the study participants and under due supervision of environmental health academic professionals of the Department of Environmental Health Sciences, Faculty of Public Health, University of Ibadan. Permission was obtained from the authorities in charge of sound studio and the data collection were only commenced after the purpose of the study had been clearly explained to the participants and informed consent obtained. Participation was made voluntary and no form of coercion was adopted. There was no undue influence on the participants. Participants were assured of confidentiality of all information obtained from them. To ensure their high level of objectivity, participants were not asked to mention their name in order to ensure anonymity.

\section{Result}

\section{Socio-Demographic characteristics}

Table 1 presents the sociodemographic characteristics of the participants. The mean age of the participants was 23.6 \pm 4.4 years, $73.8 \%$ were single while $50 \%$ were Yoruba. Majority $(78.5 \%)$ of the population had attained tertiary educational status, $28.6 \%$ claimed that they lived in residence with noisy conditions while all (100.0\%) had no hearing impairment. The overall mean Body Mass Index of the participants was 21.8 \pm 3.6 . Mean BMI for male and female participants were $21.33 \pm 2.7$ and $22.47 \pm 3.4$ respectively (Figure 3 ). These BMI value fell within the recommended WHO healthy BMI range.

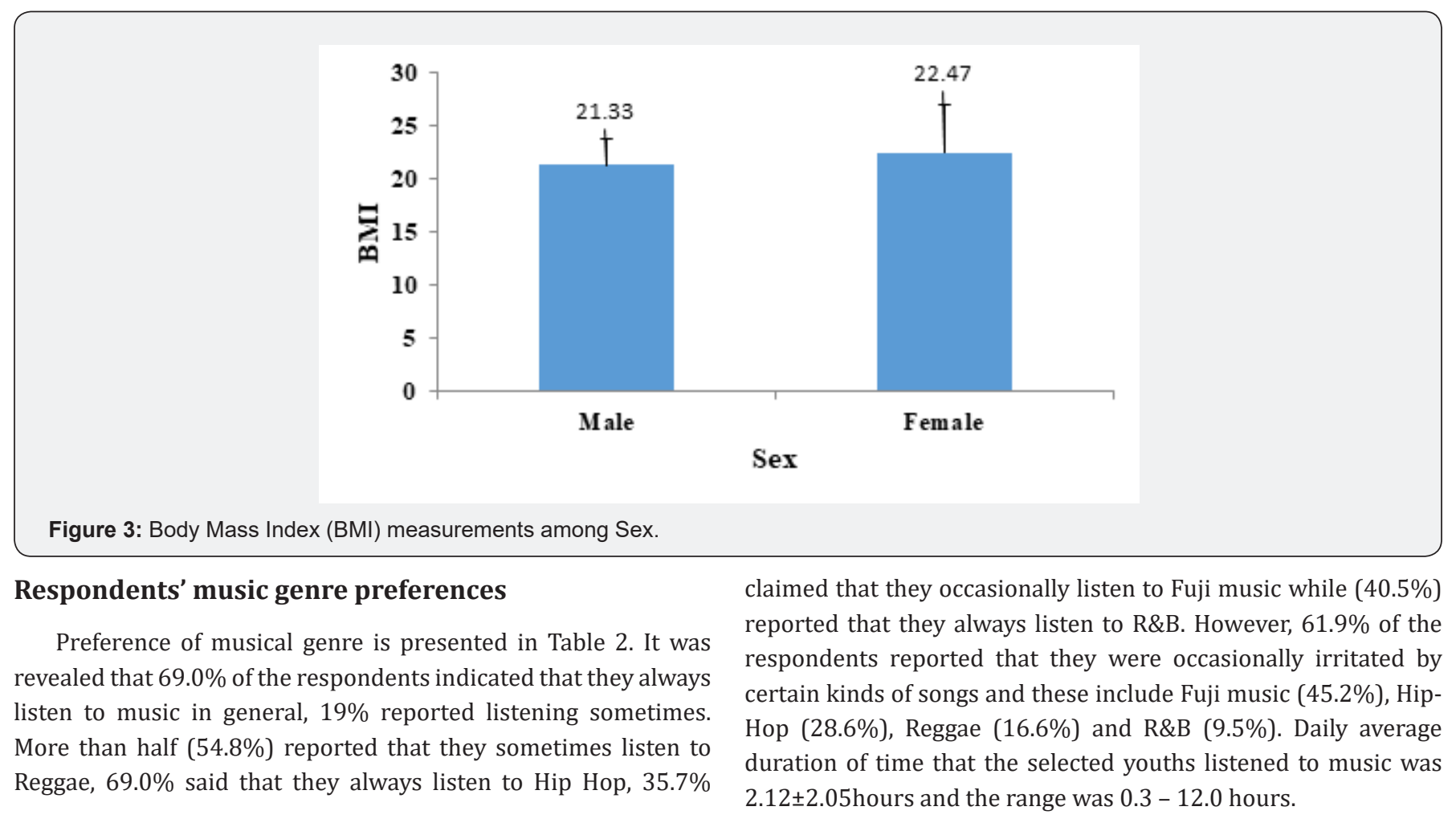




\section{Psychology and Behavioral Science International Journal}

Table 1: Socio-Demographic Characteristics.

\begin{tabular}{|c|c|c|}
\hline Characteristics & Frequency & $\%$ \\
\hline \multicolumn{3}{|c|}{ Age category (in years) } \\
\hline$<20$ & 14 & 33.3 \\
\hline $21-25$ & 14 & 33.3 \\
\hline $26-30$ & 11 & 26.2 \\
\hline $31-35$ & 3 & 7.1 \\
\hline \multicolumn{3}{|c|}{ Mean $\pm \mathbf{S D}=23.6 \pm 4.4$} \\
\hline \multicolumn{3}{|l|}{ Sex } \\
\hline Male & 21 & 50 \\
\hline Female & 21 & 50 \\
\hline \multicolumn{3}{|l|}{ Marital Status } \\
\hline Single & 31 & 73.8 \\
\hline Married & 11 & 26.2 \\
\hline \multicolumn{3}{|l|}{ Ethnicity } \\
\hline Yoruba & 21 & 50 \\
\hline Hausa & 9 & 21.4 \\
\hline Igbo & 12 & 28.6 \\
\hline \multicolumn{3}{|l|}{ Educational Status } \\
\hline Secondary & 9 & 21.4 \\
\hline Tertiary & 33 & 78.5 \\
\hline \multicolumn{3}{|c|}{ Residence Noise condition } \\
\hline Noisy & 12 & 28.6 \\
\hline Medium & 16 & 38.1 \\
\hline Quiet & 14 & 33.3 \\
\hline \multicolumn{3}{|c|}{ Hearing impairment } \\
\hline No & 42 & 100 \\
\hline
\end{tabular}

Table 2: Respondents' Music Preferences.

\begin{tabular}{|c|c|c|}
\hline Music preference & Frequency & \\
\hline Reggae Music & & 33.3 \\
\hline Always & 14 & 54.8 \\
\hline Sometimes & 23 & 11.9 \\
\hline Occasional & 5 & 69 \\
\hline Hip-Hop & & 11.9 \\
\hline Always & 29 & 19 \\
\hline Sometimes & 5 & \\
\hline Occasional & 8 & 26.2 \\
\hline Fuji & & 35.7 \\
\hline Sometimes & 11 & 38.1 \\
\hline Occasional & 15 & \\
\hline Never & 16 & 40.5 \\
\hline R\&B & 17 & 40.5 \\
\hline Always & 4 & 9.5 \\
\hline Sometimes & & \\
\hline Occasional & & \\
\hline
\end{tabular}




\section{Psychology and Behavioral Science International Journal}

\begin{tabular}{|c|c|c|}
\hline Never & 4 & 9.5 \\
\hline Frequency of listening to music & & 69 \\
\hline Always & 29 & 19 \\
\hline Sometimes & 8 & 9.5 \\
\hline Occasional & 4 & 2.4 \\
\hline Never & 1 & 61.9 \\
\hline Irritability when listen to certain types of music & 26 & \\
\hline Daily average duration of listening to music (hours) & $2.12 \pm 2.05$ (Range $=0.3-12.0)$ & \\
\hline
\end{tabular}

Perception about the influence of musical sounds on blood pressure and pulse rate

Table 3 presents the respondents' perception about the influence of musical sounds on blood pressure and pulse rate. Several $(40.5 \%)$ of the respondents indicated that choice of musical sound affected their heart rates, $42.9 \%$ said music sometimes affects their blood pressure, $28.6 \%$ state that the volume of music always affects their heart rate while $26.2 \%$ said that the volume of music choice sometimes affects their blood pressure. However, respondents mentioned inspiring (38.1\%) and soothing $(26.2 \%)$ as the major perceived benefits derived from music. Other benefits reported were relaxing, easing stress, and relaxation (Figure 4).

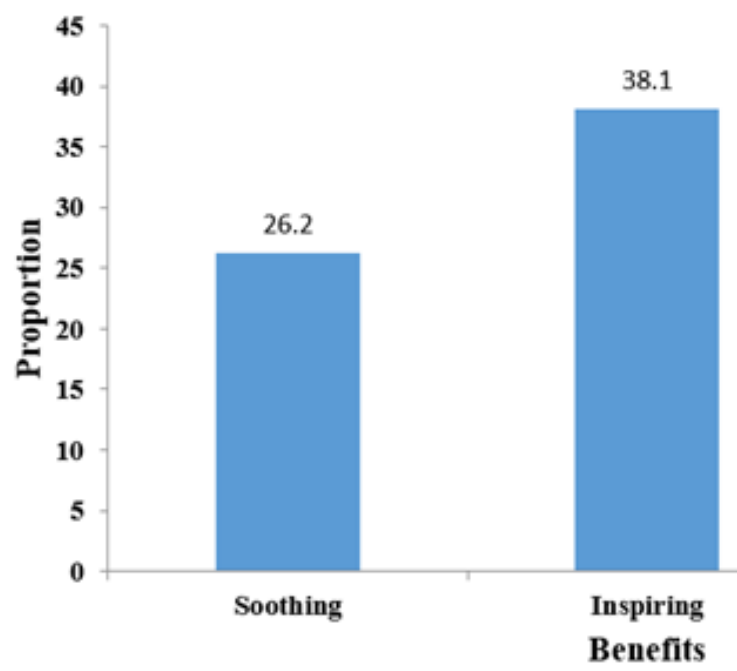

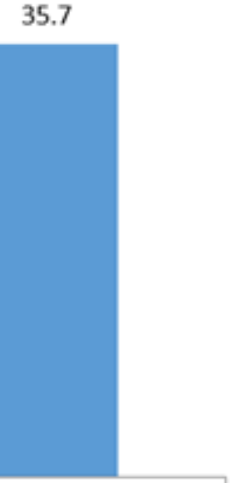

Others

Figure 4: Perceived Benefits Derived from Music According to Respondents.r.

Table 3: Perception about the influence of musical sounds on blood pressure and pulse rate.

\begin{tabular}{|c|c|c|}
\hline Perception statements & Frequency & \% \\
\hline Music choice affects their heart rate & 11 & 26.2 \\
\hline Always & 17 & 40.5 \\
\hline Sometimes & 9 & 21.4 \\
\hline Occasional & 5 & 11.9 \\
\hline Never & & 9.5 \\
\hline Music choice affects their blood pressure & 4 & \\
\hline Always & 18 & 42.9 \\
\hline
\end{tabular}




\section{Psychology and Behavioral Science International Journal}

\begin{tabular}{|c|c|c|}
\hline Occasional & 7 & 16.7 \\
\hline Never & 13 & 31 \\
\hline The volume of their music choice affects their heart rate & & 28.6 \\
\hline Always & 12 & 28.6 \\
\hline Sometimes & 12 & 11.9 \\
\hline Occasional & 5 & 31 \\
\hline Never & 13 & 23.8 \\
\hline The volume of their music choice affects their blood pressure & 10 & 26.2 \\
\hline Always & 11 & 19 \\
\hline Sometimes & 8 & 31 \\
\hline Occasional & 13 & \\
\hline
\end{tabular}

Pulse Rate and blood pressure at pre and post exposure to the selected musical genres

Comparison of Pulse Rate and blood pressure at pre- and post-exposure to the selected musical genres is presented in Table 4. Respondents pulse rate (beats/min) significantly reduced from $82.7 \pm 5.3$ at pre-exposure to $73.4 \pm 6.4,75.1 \pm 11.8,77.3 \pm 8.8$ and $74.5 \pm 7.8$ at post-exposure to R and B genre, Hip-Hop, Fuji and Reggae music respectively. Respondents' systolic blood pressure (mmHg) significantly reduced from $117.34 \pm 11.6$ at pre-exposure to $104.4 \pm 8.8,110.3 \pm 8.7$ and $106.2 \pm 16.9$ at post exposure to $R$ and B, Fuji and Reggae music respectively. However, no significant difference was observed between the systolic blood pressure

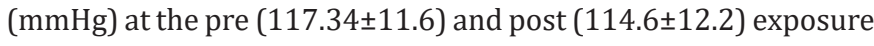
to Hip Hop. The respondents' diastolic blood pressure (mmHg) significantly reduced from $77.3 \pm 7.9$ at pre-exposure to $72.5 \pm 6.7$, $75.2 \pm 6.7$ and $74.7 \pm 6.5$ at post exposure to R\&B, Fuji and Reggae music respectively. No significant difference existed between the diastolic blood pressure $(\mathrm{mmHg})$ at the pre $(77.3 \pm 7.9)$ and post (78.5 \pm 7.9$)$ exposure to Hip Hop. Sound levels of the R\&B, Hip Hop, Fuji and Reggae music was compared with the WHO/ OSHA guideline limits $(85 \mathrm{~dB})$ as depicted in Figure 5. The sound levels $(\mathrm{dB})$ for R\&B, Hip Hop, Fuji and Reggae music were 76.3 \pm 3.2 , $76.4 \pm 3.1,81.2 \pm 2.9$ and $80.6 \pm 3.1$ respectively. Sound level for all the 4 music varieties were higher than the initial sound level of $47.7 \pm 2.3 \mathrm{~dB}$ but lower than $85 \mathrm{~dB}$ recommended by WHO/OSHA.

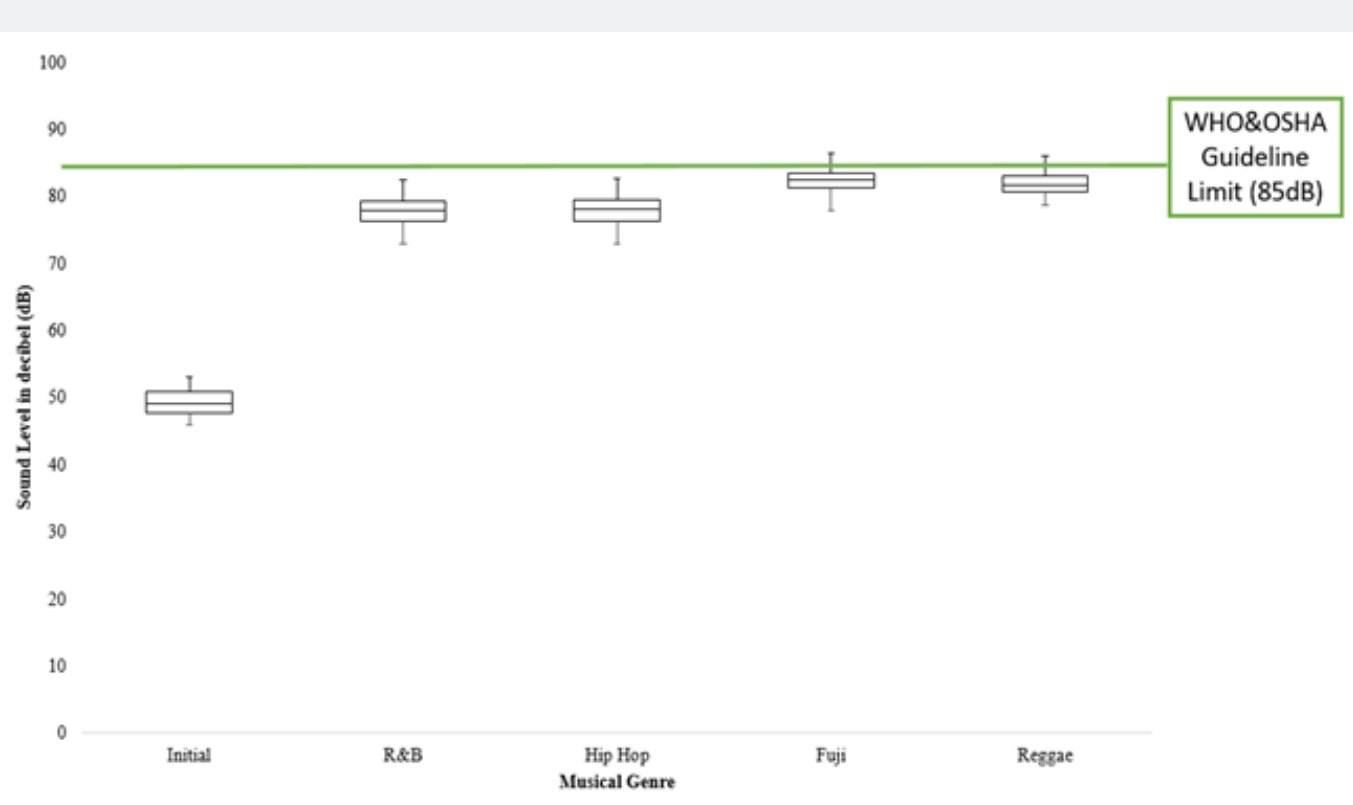

Note: Sound levels for all music types were significantly lower $(p<0.05)$ than the WHO (World Health Organisation) and OSHA (Occupational Safety and Health Administration) guideline limit except for Fuji sound level which was $(p>0.05)$ but exposure time for the participants was still $<8$ hours.

Figure 5: Comparison of Sound Levels of Different Types of Music with WHO and OSHA Guideline Limit (85dB). 
Table 4: Comparison of Pulse Rate and blood pressure at pre- and post-exposure to the selected musical genres.

\begin{tabular}{|c|c|c|c|c|c|}
\hline Musical Genre & Parameters & $\begin{array}{c}\text { Pre-exposure means } \\
\pm \text { SD }\end{array}$ & $\begin{array}{c}\text { Post-exposure means } \\
\pm S D\end{array}$ & t-test & p-value \\
\hline \multirow{3}{*}{$R$ and $B$} & Pulse (bpm) & $82.7 \pm 5.3$ & $73.4 \pm 6.4$ & 10.138 & $<0.001$ \\
\hline & Systolic Blood Pressure(mmHg) & $117.3 \pm 11.6$ & $104.4 \pm 8.8$ & 9.093 & $<0.001$ \\
\hline & Diastolic Blood Pressure (mmHg) & $77.3 \pm 7.9$ & $72.5 \pm 6.7$ & 6.503 & $<0.001$ \\
\hline \multirow{3}{*}{ Hip-Hop } & Pulse (bpm) & $82.7 \pm 6.6$ & $75.1 \pm 11.8$ & 5.032 & $<0.001$ \\
\hline & Systolic Blood Pressure(mmHg) & $117.3 \pm 11.6$ & $114.8 \pm 2.2$ & 1.645 & 0.11 \\
\hline & Diastolic Blood Pressure (mmHg) & $77.3 \pm 7.9$ & $78.5 \pm 7.9$ & 1.225 & 0.231 \\
\hline \multirow{3}{*}{ Fuji } & Pulse (bpm) & $84.2 \pm 6.8$ & $77.3 \pm 8.6$ & 4.89 & $<0.001$ \\
\hline & Systolic Blood Pressure(mmHg) & $117.3 \pm 11.6$ & $110.3 \pm 8.8$ & 4.444 & $<0.001$ \\
\hline & Diastolic Blood Pressure (mmHg) & $77.3 \pm 7.9$ & $75.2 \pm 6.7$ & 2.145 & 0.04 \\
\hline \multirow{4}{*}{ Reggae } & Pulse (bpm) & $84.2 \pm 6.8$ & $74.5 \pm 7.8$ & 6.897 & $<0.001$ \\
\hline & Systolic Blood Pressure(mmHg) & $117.3 \pm 11.6$ & $106.2 \pm 16.9$ & 4.059 & $<0.001$ \\
\hline & & & & & \\
\hline & Diastolic Blood Pressure (mmHg) & $77.3 \pm 7.9$ & $74.7 \pm 6.5$ & 3.197 & $<0.001$ \\
\hline
\end{tabular}

\section{Discussion}

This study revealed that most of the participants were single and had attained tertiary educational status. Most of the youth claimed that they lived in residences with noisy conditions, but all had claimed of no hearing impairment. The Body Mass Index of the participants fell within the recommended WHO healthy range of 18.5-24.9 which indicates that all the participants had health body mass index. Data from this study revealed that majority of the respondents always listen to music in general. Similar findings have been reported by previous studies $[6,10]$. Participants claimed that Hip-hop music was the genre they most commonly listened to but differently have more tolerance for R\&B than Reggae, Hip-Hop and Fuji. More participants believe Hip-Hop music is mostly preferred to be heard in loud volume (over $85 \mathrm{~dB}$ consistently) than Fuji music, R\&B and Reggae music, respectively. The young adults stated that they listen to music for an average of 2 hours daily and prefer using for relaxation, Hip-Hop, R and $\mathrm{B}$, Reggae and then Fuji music in this given order. Males listen to music more and this is likely a result of a better stress management coping technique adopted as seen in previous publications [11].

Data from this study revealed that several participants thought that musical sounds always have effects on their blood pressure and pulse parameters. A few (a small proportion) of the respondents believed the volume of the music always affects their heart rate and sometimes affects their blood pressure. This perception of using fast beat music for relaxation was different from a previous study by Suguna et al in 2017 [1], who observed that the heart beats in response to the tempo of the music. In this study, the major benefit of musical sound identified includes inspiration and soothing. Other benefits reported were easing stress and relaxation. This study also observed that the males dedicated more hours to listen to musicals than the females. This may be because of the gender variation in coping methods and relaxation from daily stress [11]. This study found that a significant difference existed between respondents pulse rate (beats/min) at pre-exposure and post-exposure to R\&B genre, Hip-Hop, Fuji and Reggae music respectively. A previous study has reported similar findings [1]. A significant difference was also observed between respondents' systolic blood pressure $(\mathrm{mmHg})$ at pre exposure and post exposure to R and B, Fuji and Reggae music respectively. However, no significant difference was observed between the systolic blood pressure $(\mathrm{mmHg})$ at the pre and post exposure to Hip Hop. These findings indicated that Hip-Hop had significant reduction in pulse rate, but did not have significant effect on blood pressure and parameters. This study found that R\&B genre had significant reduction effect on both the blood pressure and pulse rates. The systolic blood pressure significant reduction was similar with the systolic blood pressure findings upon exposure of male study participants to slow beat [1]. However, Bernadi et al., [4] findings revealed a decrease in heart rate but non-significant effect on blood pressure after listening to slow music. 
Participants who exposed to Fuji music also had significant reduction in systolic blood pressure and pulse levels. These findings indicated that Fuji music had effect in reducing blood pressure and pulse levels. Furthermore, Reggae music showed significant effect in reduction of systolic blood pressure and pulse levels. These results agreed with a previous study which showed that music can be used as an adjuvant to reduce anxiety and stress [12]. The study also revealed that the sound level for R\&B, Hip Hop, Fuji and Raggae music were higher than the initial sound level of $47.7 \pm 2.3 \mathrm{~dB}$ but lower than $85 \mathrm{~dB}$ recommended by WHO/OSHA. This indicated that the sound level of all the four types of music were within the healthy limits recommended by WHO/OSHA. In this study, R\&B was most effective in decreasing blood pressure and pulse, which was followed by Reggae, then Fuji music before Hip-Hop respectively. This result agreed with the work of Thorne et al., [13] who stated that generally, people reported that while listening to fast beat music, they get excited whereas slow beat music makes them relax.

\section{Conclusion}

This study revealed that most of the youth claimed that they lived in residences with noisy conditions but none complained of hearing impairment. The Body Mass Index of the participants fell within the recommended WHO healthy range which indicates that all the participants had healthy or acceptable body mass index. Majority of the respondents always listen to music in general. Participants revealed that they have more tolerance for R\&B than Reggae, Hip-Hop and Fuji. The young adults stated that they listen to music for an average of 2 hours daily and prefer using for relaxation. In this study, the major benefit of musical sound identified includes inspiration and soothing. Other benefits reported were easing stress and relaxation. This study also observed that the males dedicated more hours to listen to musicals than the females. A significant difference existed between respondents pulse rate (beats/min) at pre-exposure and post-exposure to R\&B genre, Hip-Hop, Fuji and Reggae music respectively. A significant difference was also observed between respondents' systolic blood pressure (measured as $\mathrm{mmHg}$ ) at pre exposure and post exposure to R and B, Fuji and Reggae music, respectively. However, no significant difference was observed between the systolic blood pressure $(\mathrm{mmHg}$ ) at the pre and post exposure to Hip Hop. The study also revealed that the sound level for R\&B, Hip Hop, Fuji and Raggae music were within the healthy limits recommended by WHO/OSHA. In this study, R\&B was most effective in decreasing systolic blood pressure and pulse rate, which was followed by Reggae, then Fuji music before HipHop, respectively. In this study, use of slow beat musical genres such as R\&B, Reggae and then Fuji music, are not only useful for pleasure but also have significant effect on the pulse rate and systolic blood pressure. There should be more and wider research into local indigenous musicals of public health interest and their effects upon health. Also, awareness should be increased on the use of simulated environmental sounds and musicals in addition to other techniques to aid rest and to improve and advance the treatment of hypertension.

Acknowledgement: The authors wish to acknowledge all the young adults who consented to participate in the study.

Conflict of interest: None declared.

\section{References}

1. Suguna S, Deepika K (2017) The Effects of music on Pulse rate and Blood pressure in healthy young adults. International Journal of Research in Medical Sciences 5(12): 5268-5272.

2. Kock S, Anderson T, Kolstad HA, Kafoed Nielsen B, Wiesler F (2004) Surveillance of noise exposure in the Danish workplace: A base-line survey. Occup Environ Med 61: 838-843.

3. Schwanz S (2015) Music and the Unconscious Mind: A Proposed Study Examining the Autonomic Nervous System in Response to Basic Musical Rhythms. Western Undergraduate Psychology Journal 3(1).

4. Bernardi L, Porta C, Casucci G, Balsamo R, Bernardi NF, et al. (2009) Dynamic interactions between musical, cardiovascular, and cerebral rhythms in humans. Circulation 30(25): 3171-3180.

5. Aluede CO (2006) Music Therapy in Traditional African Societies: Origin, Basis and Application in Nigeria. J Hum Ecol 20(1): 31-35.

6. Abiodun F (2011) Song Forms in Ekiti Musical Traditions. Journals of the Association of Nigerian Musicologists 4(6): 68-82.

7. Nnamani SN (2016) The Diagnostic and Therapeutic Role of Music in Mental Health: Implications to National Development. American Journal of Educational Research 4(1): 104-107.

8. National Population Commission (NPC) (2016) Oyo state population by local government and sex.

9. Chang J (2005) Can't Stop Won't Stop: A History of the Hip Hop Generation. St. Martin's Press, New York, United States p.90.

10. Adeola TS (2001) Contemporary Nigerian popular music: A tool for national development. Nigeria Theatre Journal 6(1): 80-85.

11. Katrina E, Derek M, Julie OA, Roland J, Marino AB (2015) "If you do nothing about stress, the next thing you know, you're shattered": Perspectives on African American men's stress, coping and health from African American men and key women in their lives. Soc Sci Med 15(139): 107-114.

12. Agrawal A, Makhijani N, Valentini P (2013) The effect of music on heart rate. J EmergInvestig 25: 1-5.

13. Thorne J, Shannon J, Spencer C (2002) The effects of music on heart rate and blood pressure. International Journal of Research in Medical Sciences 1: 1 . 

(C) Comons Attribution 4.0 License DOI:10.19080/PBSIJ.2020.16.555927

\section{Your next submission with Juniper Publishers} will reach you the below assets

- Quality Editorial service

- Swift Peer Review

- Reprints availability

- E-prints Service

- Manuscript Podcast for convenient understanding

- Global attainment for your research

- Manuscript accessibility in different formats

( Pdf, E-pub, Full Text, Audio)

- Unceasing customer service

Track the below URL for one-step submission https://juniperpublishers.com/online-submission.php 